\title{
ORIENTAÇÕES METODOLÓGICAS PARA A CONSTITUIÇÃO DE UM BANCO DE DADOS LEXICAL PARA A ELABORAÇÃO DE DICIONÁRIOS PEDAGÓGICOS
}

\author{
METHODOLOGICAL GUIDELINES FOR THE CONSTITUTION OF A LEXICAL \\ DATA BANK FOR THE ELABORATION OF PEDAGOGICAL DICTIONARIES
}

\begin{abstract}
Adilson do Rosário TOLEDO
Docente da Universidade Estadual do Paraná - UNESPAR Pesquisador do Programa de Pós-Graduação em Estudos da Tradução - PÓS-DOC PGET/REUNI/UFSC
\end{abstract}

Adja Balbino de Amorim Barbieri DURÃO Docente do Programa de Pós-Graduação em Linguística - UFSC Docente do Programa de Pós-graduação em Estudos da Tradução - UFSC Professora colaboradora do Programa de Pós-Graduação em Estudos da Linguagem - UEL

Bolsista de Produtividade do CNPq

\begin{abstract}
Resumo
Este trabalho se insere na área da Lexicografia (BÉJOINT, 2000; BORBA, 2003; WELKER, 2004; WERNER, DURÃO, RUANO, 2009; DURÃO, 2009, 2010), mais especificamente, no campo da Metalexicografia, na interface com a Linguística Contrastiva (LADO, 1957) em seu modelo contemporâneo (SELINKER, 1994; DURÃO, 2007). O objetivo fundamental desta pesquisa é a investigação de metodologia adequada para a elaboração de dicionário pedagógico contrastivo em língua materna. Parte-se do pressuposto de que as estratégias de desenvolvimento de interlíngua, na aquisição/aprendizagem de crianças em fase inicial de escolarização, ficam potencializadas com o uso de dicionário pedagógico de qualidade, cujas unidades léxicas sejam originadas da própria comunidade de fala. Um dos recursos metodológicos à disposição para a construção de um Banco de Dados Lexical para este fim pode estar nos fundamentos da Teoria da Variação e Mudança Linguísticas (WEINREICH, LABOV, HERZOG, 1968; LABOV, 1972; SILVA-CORVALÁN, 1989; TARALLO, 1990). O trabalho se desenvolverá em três etapas coordenadas: análise instrumental, coleta de dados e apresentação de resultados.
\end{abstract}

Palavras-chave: Interlíngua. Dicionário. Aquisição. Aprendizagem.

\begin{abstract}
This work is inserted in Lexicographic studies (BÉJOINT, 2000; BORBA, 2003; WELKER, 2005; WERNER, DURÃO, RUANO, 2009; DURÃO, 2009, 2010), specifically in the field of Metalexicography, in the interface with Contrastive Linguistic studies (LADO, 1957) in its contemporary model (SELINKER, 1994; DURÃO, 2007). The main purpose of this research deals with the methodological investigation to construct a pedagogical contrastive dictionary in the mother tongue. We suppose that the strategies of interlanguage development in acquisition/apprenticeship can be potentialised with the use of a quality adequate pedagogical dictionary. But the lexical units must be generated from the inner community of speech. We can find methodological approaches at our disposal to construct a Lexical Data Bank in the Empirical Foundations of a Theory of Language Change (WEINREICH, LABOV, HERZOG, 1962; LABOV, 1972; SILVA-CORVALÁN, 1989; TARALLO, 1990). This work will be developed in three coordinated phases: instrumental analysis, data collection, and presentation of results.
\end{abstract}

Keywords: Interlanguage. Dictionary. Acquisition. Apprenticeship. 


\section{INTRODUÇÃO}

A interlíngua pode ser definida como o sistema linguístico de aprendizes de línguas e socioletos (DURÃO, 2007). No enfoque do letramento, o estudo dos estágios de interlíngua acontece mediante a análise de um sistema gramatical funcional em contraste com o sistema gramatical canônico apregoado pela escola. Neste caso, o desenvolvimento de interlíngua pode ser estimulado através de vários recursos didático-instrumentais, como o reforço das estratégias cognitivas inerentes ao aprendiz, a exposição a materiais didáticos de qualidade e atividades sociointerativas extraclasse. A respeito desta temática, Toledo (2011) afirma que o desenvolvimento de interlíngua no letramento de crianças em fase inicial de escolarização pode ser potencializado pelo uso de dicionário pedagógico adequado.

O desenvolvimento de interlíngua, em termos de aquisição/aprendizagem de conceitos empíricos fora do ambiente escolar (práticas socioeducativas) e conceitos teóricos e científicos no ambiente escolar, tem lugar juntamente com o desenvolvimento cognitivo. No processo de aprendizagem linguística, o conhecimento teórico e científico deve ser pensado em termos de letramento de qualidade (escrita com autoria, leitura com proficiência e oralidade com argumentação). Assim, o desenvolvimento de interlíngua na alfabetização se concretiza com o letramento de qualidade.

Os primeiros estímulos para o desenvolvimento de interlíngua podem ser dados, na educação infantil, pelos chamados exercícios de prontidão. Já na fase de alfabetização, a criança passa a testar diversas hipóteses (estratégias cognitivas) de aprendizagem que a incentivam na aquisição do sistema léxico-gramatical. As principais delas são a memorização, a transferência e a sobregeneralização de regras que se revelam nas diversas habilidades linguísticas.

Em seu estudo, Toledo (2011) prioriza o aspecto lexical, que reflete diretamente o conteúdo semântico da gramática e constitui o todo léxico-semântico da língua. No processo de aquisição/aprendizagem linguística, o domínio e o aprimoramento do conjunto léxico-semântico da língua funcionam como instrumentos estimulantes do desenvolvimento de interlíngua. Um dos recursos privilegiados para o reforço da memória léxico-semântica no letramento está no uso adequado do dicionário pedagógico. A mesma pesquisa concluiu que, em sua maioria, os dicionários à disposição nas escolas não cumprem com o papel pedagógico que, algumas vezes, dizem desempenhar.

Este fato permitiu a proposição de novas pesquisas no intuito de estudar o assunto. As duas questões básicas que afloram destas reflexões gravitam em torno da arquitetura de dicionários (entre eles, o dicionário pedagógico) e a seleção das unidades léxicas de entrada. Para se estudar a arquitetura que vai modelar a construção de um dicionário qualquer, deve-se pautar por uma consistente base lexical. Logo, a constituição de um banco de dados lexical precede à idealização da arquitetura do dicionário. Neste contexto, surgiu o presente trabalho, que se insere na área dos estudos lexicográficos, mais precisamente da Metalexicografia (BÉJOINT, 2000; BORBA, 2003; WELKER, 2005; WERNER, DURÃO, RUANO, 2009; DURÃO, 2009, 2010), na interface com a Linguística Contrastiva (LADO, 1957) em seu modelo contemporâneo (SELINKER, 1994; DURÃO, 2007).

Normalmente, os lexicógrafos pautam a seleção de verbetes que compõem seus dicionários pelo aspecto referencial ou funcional. No primeiro caso, as unidades léxicas remetem a uma língua hipotética e idealizada, muito embora descrita em vários dicionários (entre os quais o Novo Dicionário da Língua Portuguesa, de Aurélio Buarque de Holanda Ferreira) como formada de palavras e expressões vivas. No segundo caso, a seleção das unidades léxicas que figurarão no dicionário pretende direcionar-se pelo uso real e, portanto, teoricamente, tais dicionários concebem a língua como fato social. 
Os dicionários, entretanto, recorrem preferencialmente a abonações baseadas em corpora escritos. A pergunta que se coloca é: até que ponto a seleção de unidades de entrada de um dicionário de cunho pedagógico pode se basear, exclusivamente, em tal premissa? A procura por uma resposta satisfatória a essa pergunta direciona esta pesquisa, que tem por objetivo o estudo de metodologia adequada para a seleção das unidades léxicas na elaboração de dicionário pedagógico em língua materna. Propomos que as unidades léxicas que devem constituir o banco de dados lexical surjam da própria comunidade de fala.

Uma das opções metodológicas para a construção de um Banco de Dados Lexical para este fim pode estar nos fundamentos da Teoria da Variação e Mudança Linguísticas (WEINREICH, LABOV, HERZOG, 1962; LABOV, 1972; SILVA-CORVALÁN, 1989; TARALLO, 1990). Assim sendo, partimos destes pressupostos: 1. Na aquisição/aprendizagem, as estratégias de desenvolvimento de interlíngua são potencializadas com o uso de dicionário pedagógico de qualidade; 2. Entendemos por dicionário pedagógico de qualidade a obra em que as unidades lexicais originam-se da própria comunidade de fala, ou seja, da realidade que envolve o aprendiz. A construção de um Banco de Dados Lexical serve a este propósito.

\section{DESENVOLVIMENTO DA PESQUISA}

A partir das concepções apresentadas anteriormente, foi delineada uma pesquisa empírica e passamos a desenvolvê-la junto a uma comunidade 'isolada' específica. Optamos pelo trabalho com pescadores das ilhas do litoral paranaense. A longo prazo, o trabalho envolve seis comunidades, caracterizadas na seção seguinte. As pesquisas foram iniciadas na comunidade de pescadores artesanais da ilha (vila) de Amparo. Ressaltamos que todas as seis comunidades abrangidas pela pesquisa se inserem na modalidade de Educação do Campo ${ }^{1}$.

A princípio, a necessidade de empreender um estudo para a constituição de um banco de dados lexical para a elaboração de dicionários pedagógicos surgiu de algumas constatações problematizadoras:

a. Em sua maioria, os dicionários pedagógicos existentes no mercado não cumprem, de fato, suas funções didático-pedagógicas;

b. A seleção das unidades lexicais utilizadas como informação de entrada dos dicionários pedagógicos não apresenta, nesses dicionários, um eixo definido;

c. A seleção das unidades lexicais dos dicionários pedagógicos, em geral, não costuma obedecer a critérios sociolinguístico-antropológico-contrastivos que visem a contribuir para o desenvolvimento de interlíngua por aprendizes pertencentes a comunidades com características específicas (como da Educação do Campo, por exemplo).

Os primeiros passos dos trabalhos na ilha de Amparo ocorreram com a pesquisa do perfil socioinstrucional da comunidade ${ }^{2}$. Logo em seguida, depois de alguns contatos prévios com a comunidade por vários dias seguidos, começamos a fazer entrevistas em vídeo ${ }^{3}$.

\footnotetext{
${ }^{1}$ De acordo com DCE, Educação do Campo (2006, p. 22) 'a identidade dos povos do campo comporta categorias sociais como posseiros, bóias-frias, ribeirinhos, ilhéus, atingidos por barragens, assentados, acampados, arrendatários, pequenos proprietários ou colonos ou sitiantes - dependendo da região do Brasil em que estejam - caboclos dos faxinais, comunidades negras rurais, quilombolas e, também, as etnias indígenas'.

${ }^{2} \mathrm{O}$ perfil da comunidade ficou determinado através de um Questionário Socioinstrucional (conforme Anexo 1), respondido por 73 pescadores(as). Existem outros trabalhos sendo desenvolvidos nessas comunidades de pescadores, o que facilitou o acesso aos informantes. Um desses trabalhos é o Projeto de Amparo ao Pescador (PAP).

${ }^{3}$ Consultar Anexo II. As entrevistas sofreram adequações posteriores.
} 


\subsection{A questão do isolamento das comunidades}

O Brasil está passando por um processo rápido de urbanização. O termo urbanização pode ser entendido, basicamente, segundo duas acepções: a) pelo aspecto demográfico, trata-se do êxodo da população do campo em direção às cidades; b) pelo aspecto da qualidade de vida, refere-se ao acesso aos bens de consumo e serviços a que aspira a população do campo, na tentativa de aproximação aos estilos de vida da população das cidades. Neste último caso, embora a vantagem da modernidade que possa trazer o estilo de vida das cidades não seja uma opinião unânime, a urbanização está representada na energia elétrica, que possibilita maior acesso às diferentes mídias, na instalação de rede de saneamento básico, em melhor acesso aos recursos de saúde e educação, em incremento comercial, etc.

Bortoni-Ricardo (2011), enfocando o primeiro aspecto, comprova a interferência do estilo de vida na constituição dialetal e, consequentemente, na organização léxico-semântica da língua. Esta pesquisadora empreendeu um trabalho exaustivo de documentação e análise do surgimento de um dialeto urbano entre a população de migrantes de Brazlândia, cidade-satélite de Brasília, oriundo da transformação de um dialeto rural pelo contato com o dialeto urbano de Brasília. Bortoni-Ricardo (2011), embasada no conceito de redes sociais, discute feições fonológicas e morfossintáticas do surgimento desse dialeto que a autora denomina de rurbano e pode ser considerado como uma categoria dialetal intermediária entre o dialeto rural e o dialeto urbano. A leitura do trabalho de Bortoni-Ricardo (2011) permite supor que, atualmente, em consequência da era da informação, poucas são as comunidades verdadeiramente isoladas.

A presente pesquisa desenvolvida entre as comunidades de pescadores artesanais do litoral paranaense aborda o segundo aspecto apontado por Bortoni-Ricardo (2011) e tratará do mapeamento da oralidade dessas comunidades. Relativamente ao isolamento parcial dessas comunidades, desde o princípio dos estudos, concordamos com as argumentações de BortoniRicardo (2011). Ao mesmo tempo, consideramos de muita importância os dados da oralidade dessas comunidades, tanto para a preservação do arcabouço linguístico do português falado no Brasil como para subsidiar um Banco de Dados Lexical para a construção de dicionários.

$\mathrm{O}$ interesse por pesquisa desta natureza surgiu a partir do contato frequente mantido pelos pesquisadores com as comunidades de pescadores da região de Paranaguá, litoral do Paraná, a partir do ano 2000. A saber, as comunidades de pescadores artesanais das vilas (ilhas) de Amparo, Piaçaguera, Teixeira, Eufrasina, Europinha e São Miguel (para maiores referências sobre a região, vide Fig. 1). Intuitivamente, percebemos que os habitantes desses locais, em sua quase totalidade, pescadores nascidos ali, recusam a migração para a cidade. Os mais velhos revelam desejar um estilo de vida melhor do que de profissionais da pesca para os filhos. Por sua vez, os jovens consideram melhor o estilo de vida da cidade, embora prefiram, em sua maioria, permanecer no lugar.

No âmbito deste trabalho, as pesquisas iniciaram na localidade de maior contingente populacional, a comunidade de Amparo. Apesar de estarmos apenas nos primeiros meses de pesquisa, algumas informações podem ser apresentadas. A partir dessas informações iniciais, nesta pesquisa procuraremos analisar a interferência do estilo de vida urbano na constituição dialetal da população ribeirinha de Amparo, utilizando um percurso inverso ao percorrido pelos informantes de Bortoni-Ricardo (2011) e as consequências na relação entre lexicalização, conservação e inovação lexical e gramatical (semântica) daí decorrentes. Por outro lado, ressaltamos, de novo, faz-se urgente o resgate e preservação do vernáculo dessas comunidades e o estudo da oralidade de seus integrantes. Um estudo contrastivo diageracional nos permitirá comparar os processos de conservação e inovação linguísticas em curso nessas ilhas por meio do estabelecimento de crenças e atitudes frente ao dialeto urbano. 
Ao mesmo tempo, tentaremos propor orientações metodológicas de coleta de dados para a seleção da base lexical para estudos metalexicográficos e também apresentar dados da língua em uso no português do Brasil.

Neste contexto, sobressai a pesquisa de dicionários de caráter contrastivo que sirvam de parâmetro para a construção de dicionários pedagógicos. Partimos do pressuposto de que alguns procedimentos metodológicos utilizados no âmbito das pesquisas da Variação e Mudança Linguísticas (e mesmo da Dialetologia e Etnometodologia) podem servir para este fim, principalmente no que diz respeito à coleta de dados empíricos que permitam amostragens da oralidade dos moradores das comunidades de pescadores dessa região litorânea. A partir da realidade destas comunidades citadas, estudaremos o vernáculo revelado pelas entrevistas com moradores locais.

\title{
3 DESCRIÇÃO FÍSICA DA REGIÃO ENVOLVIDA NA PESQUISA
}

A formação da Villa de Nossa Senhora do Rozario de Pernaguá ou Paranaguá ${ }^{4}$, de acordo com Santos (1850 [1922], p.15) remonta a 6 de janeiro de 1646, com a inauguração do pelourinho. Oficialmente, porém, a fundação da Villa está confirmada pelo mesmo pesquisador com a data de 29 de julho de 1648, quando foi constituído como capitão-mor e ouvidor Gabriel de Lara.

A cidade de Paranaguá está situada na grande baía de mesmo nome, assim descrita por Santos (1850 [1922]):

\begin{abstract}
A grande Bahia terá de comprimento de Leste a oeste, 6 ou 7 legoas, para mais de 3 na maior largura, sua forma mui irregular com vários recantos; a porção mais septentrional he a Bahia dos Pinheiros; a mais çentral, a das Laranjeiras; e a mais occidental a de Antonina, formando todas conjunctamente, hua so no interior das três barras. Neste golfo, estão semeadas mais de 30 ilhas e pequenos ilhotes; alguas com duas e mais legoas de comprido e outras menores; revestidas de verdes mattas, fazendo realçar as agoas azuladas destas Bahias; e no circuito de seus contornos vão dezaguar mais de 80 rios grandes e caudalozos, a mór parte navegaveis, em distançia de 8 a 10 legoas, e immensos ribeirões e galhos lateraes que a elles se vem juntar, e todos vão tributar seu curso nas Bahias (SANTOS, 1850 [1922], p. 59).
\end{abstract}

A região envolvida na presente pesquisa está localizada na baía das Laranjeiras, que fica de frente para o terminal portuário de Paranaguá. Podemos supor que as vilas de pescadores já existiam na primeira metade do século XIX, conforme comprova a alusão feita à ilha do Teixeira no trecho seguinte:

Continuase agora a descripção da Bahia desde a fóz do Rio Cubatão ao de S. João, e dali pela margem opposta do grande braço que fas a Baía. Para deste lado de Oeste, continua outra costeira te a ponta ou isthmo de terra denominado - dos Pinheiros - e que fica fronteiro da ilha do Teixeira (SANTOS, 1850 [1922], p. 62).

Estas informações servem para comprovar a antiguidade das localidades pesquisadas e para situar a época da ocupação dessas paragens com a colonização de Paranaguá, no século XVII. A

\footnotetext{
${ }^{4}$ Respeitamos a grafia de referência neste e em outros casos mencionados a seguir, retirados de Santos (1850 [1922]).
} 
imagem apresentada a seguir, demarca a região geográfica onde se localizam as comunidades envolvidas na pesquisa:

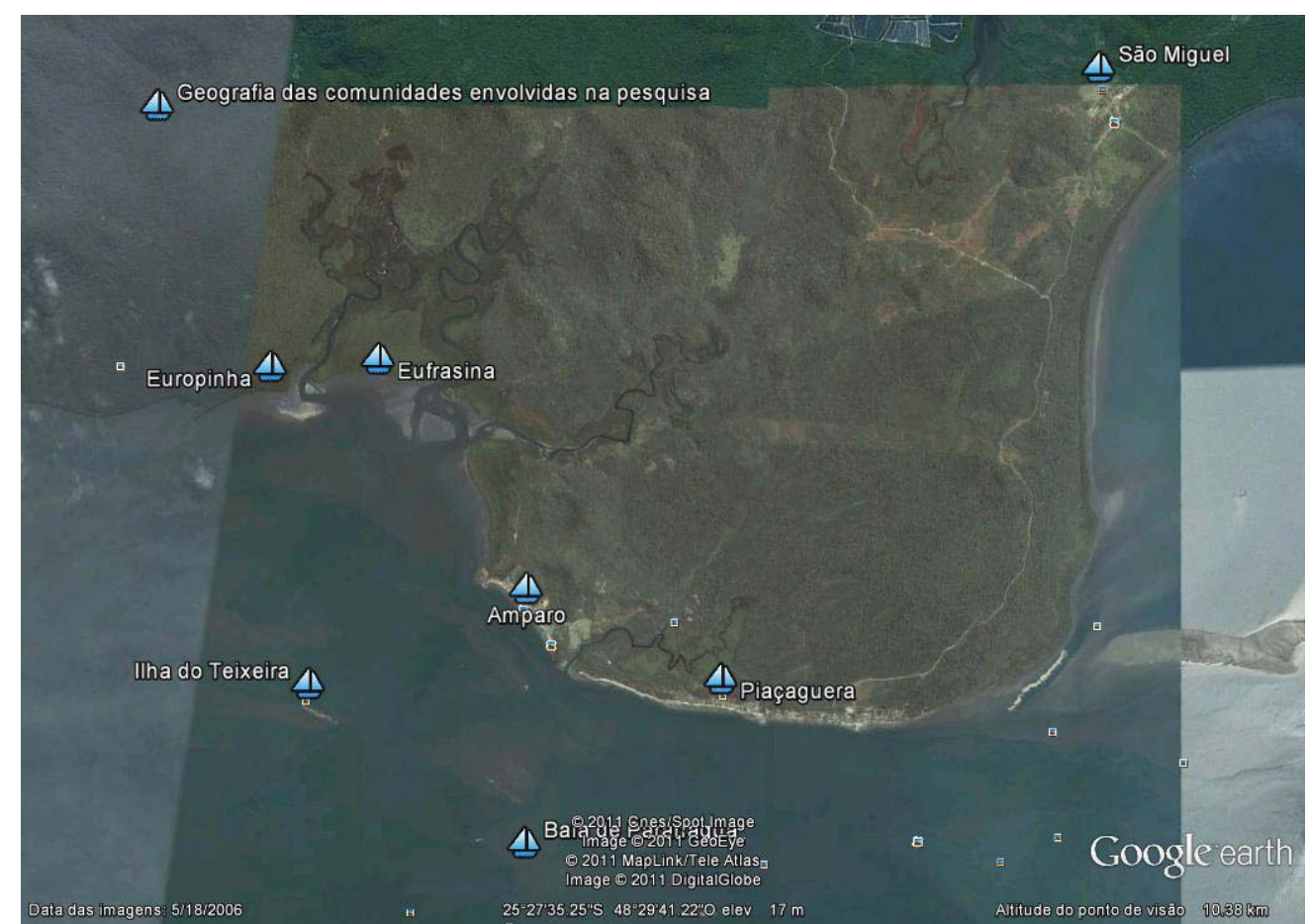

Figura 1: Imagem de satélite da região que compreende as comunidades envolvidas na pesquisa

\section{PERFIL DA AMOSTRA E SELEÇÃO DOS INFORMANTES}

De acordo com Freitas (1999, p. 55), Paranaguá foi “a primeira região da costa meridional a ser percorrida pelos portugueses, logo depois das primeiras viagens exploradoras [...] através dos primeiros moradores de Cananéia e vicentinos, náufragos ou desterrados, entre os anos de 1501 e seguintes". A povoação efetiva do litoral começou na Ilha da Cotinga ${ }^{5}$ pelo ano de 1570 , na época em que, conforme dados históricos, Domingos Peneda fundou o primeiro povoado ao abrigo dos piratas e dos índios carijós que dominavam a região. Gradativamente, atraídos pelo boato de ouro, estes primeiros povoadores exploraram os diferentes recôncavos, rios e sertões da região até chegar, definitivamente, ao continente, às margens do Rio Itiberê, onde, mais tarde, surgiu a cidade de Paranaguá.

Presume-se que as comunidades pesqueiras da região de Paranaguá sejam formadas por descendentes desses primeiros colonizadores que chegaram ao litoral, muito provavelmente, junto com Domingos Peneda (por volta de 1550) e com Gabriel de Lara (por volta de 1600).

A região é considerada área de preservação ambiental, de difícil acesso e com poucas benfeitorias. Recentemente, a partir da década de 90, chegaram os atendimentos em energia elétrica e água potável. O perfil da amostra pode ser descrito, então, como pescadores artesanais de uma faixa de mar confinada ao entorno da comunidade (para diferenciar dos pescadores de alto mar), em sua maioria nascidos e moradores das comunidades em torno da baía, que se aventuram, eventualmente, ao continente.

\footnotetext{
${ }^{5}$ Ilha contígua a Paranaguá.
} 
A constituição da amostra (geral) para a seleção dos informantes foi determinada pelo número estimado de habitantes das localidades envolvidas na pesquisa e obedece à porcentagem de habitantes, a partir da qual se constituiu a amostra. As tabelas a seguir apresentam a distribuição da amostra, de forma a constituir-se o total de 30 informantes que desejávamos entrevistar.

Tabela 1: Distribuição populacional das comunidades envolvidas na pesquisa

\begin{tabular}{c|c|c}
\hline Localidade & Número de Famílias & Número de habitantes $^{\mathbf{6}}$ \\
\hline Amparo & 120 & 600 \\
Piaçaguera & 35 & 175 \\
São Miguel & 30 & 150 \\
Europinha & 30 & 150 \\
Eufrasina & 30 & 150 \\
Teixeira & 30 & 150 \\
Total & 275 & 1375 \\
\hline
\end{tabular}

Tabela 2: Percentual de habitantes de cada localidade em relação ao total do universo

\begin{tabular}{c|c}
\hline Localidade & \% \\
\hline Amparo & 43,64 \\
Piaçaguera & 12,73 \\
São Miguel & 10,91 \\
Europinha & 10,91 \\
Eufrasina & 10,91 \\
Teixeira & 10,91 \\
Total & 100,00 \\
\hline
\end{tabular}

Tabela 3: Projeção do número de informantes por localidade

\begin{tabular}{c|c}
\hline Localidade & Número de informantes \\
\hline Amparo & 13 \\
Piaçaguera & 4 \\
São Miguel & 3 \\
Europinha & 3 \\
Eufrasina & 4 \\
Teixeira & 3 \\
Total & 30 \\
\hline
\end{tabular}

O número de pontos de sondagem foi fixado em cada uma das seis regiões da pesquisa, ou seja, em cada comunidade de pescadores. A seleção dos informantes observa a proporção de informantes em cada vila. De maneira geral, o informante deve preencher o seguinte perfil:

a) Ser nascido no local;

b) Ter idade entre 7 a 80 anos;

c) Escolaridade: ser analfabeto ou ter cursado, no máximo, o ensino médio;

d) Apresentar boa condição de fonação;

6 O cálculo aproximado do número de habitantes estipula em torno de cinco pessoas por família. 
e) Aceitar as condições da entrevista;

f) Não se ter ausentado do local por muito tempo.

A partir do exposto, o perfil (geral) dos informantes deve obedecer à seguinte tabela:

Tabela 4: Perfil dos informantes

\begin{tabular}{|c|c|c|c|c|c|c|c|c|}
\hline \multirow{2}{*}{$\begin{array}{l}\text { Faixa etária } \\
\text { Localidade }\end{array}$} & \multicolumn{2}{|c|}{$\begin{array}{c}1^{\mathrm{a}} \text {. Faixa } \\
(7 \text { a } 17 \text { anos })\end{array}$} & \multicolumn{2}{|c|}{$\begin{array}{c}2^{\mathrm{a}} . \text { Faixa } \\
(18 \text { a } 29 \text { anos })\end{array}$} & \multicolumn{2}{|c|}{$\begin{array}{c}3^{\mathrm{a}} . \text { Faixa } \\
(30 \text { a } 59 \text { anos })\end{array}$} & \multicolumn{2}{|c|}{$\begin{array}{c}4^{\mathrm{a}} . \text { Faixa } \\
(60 \text { anos e acima })\end{array}$} \\
\hline & H & $\mathbf{M}$ & $\mathbf{H}$ & $\mathbf{M}$ & $\mathbf{H}$ & $\mathbf{M}$ & H & $\mathbf{M}$ \\
\hline $\begin{array}{c}\text { Amparo } \\
\text { Piaçaguera } \\
\text { São Miguel } \\
\text { Europinha } \\
\text { Eufrasina } \\
\text { Teixeira }\end{array}$ & $\begin{array}{l}1 \\
1\end{array}$ & $\begin{array}{l}2 \\
1 \\
1\end{array}$ & $\begin{array}{l}1 \\
1\end{array}$ & $\begin{array}{l}2 \\
1\end{array}$ & $\begin{array}{l}2 \\
1\end{array}$ & $\begin{array}{l}2 \\
1\end{array}$ & $\begin{array}{l}1 \\
1\end{array}$ & $\begin{array}{l}1 \\
1 \\
\end{array}$ \\
\hline
\end{tabular}

Como ressaltamos anteriormente, a coleta de dados iniciou-se na maior comunidade, que é a ilha de Amparo. Os trabalhos em Amparo foram iniciados com uma reunião com os pescadores, convocada pela Associação de Moradores, na qual foi solicitado que eles preenchessem a ficha socioinstrucional (73 pescadores se mostraram dispostos a participar do projeto). A partir disso, e da análise da ficha socioinstrucional, o primeiro procedimento para a coleta de dados foi selecionar 13 informantes que preenchessem aos requisitos apresentados para a pesquisa e que se dispusessem a ser entrevistados. A partir dessa triagem inicial, os informantes foram selecionados e planejamos gravações em vídeo para obtenção de amostra da oralidade da comunidade. É necessário ressaltar que o mesmo procedimento de pesquisa será seguido em todas as localidades.

Assim sendo, de um universo de 73 pescadores(as) que responderam ao inquérito e se tornaram informantes potenciais, 13 foram contatados e se dispuseram a colaborar. Logo, o universo de participantes potenciais da pesquisa está formado por um leque de 73 sujeitos pescadores e pescadoras e seus filhos, que se organizam de acordo com as tabelas 5 e 6:

Tabela 5: Participantes potenciais do projeto em Amparo, de acordo com a idade

\begin{tabular}{c|c|c|c|c}
\hline $\mathbf{1 4}-\mathbf{1 7}$ anos & $\mathbf{1 8}-\mathbf{2 9}$ anos & $\mathbf{3 0}-\mathbf{5 9}$ anos & $\mathbf{6 0}$ anos e acima & Total \\
\hline 17 & 18 & 34 & 4 & 73 \\
\hline
\end{tabular}

Tabela 6: Participantes potenciais do projeto em Amparo, de acordo com o sexo

\begin{tabular}{c|c}
\hline Homens & Mulheres \\
\hline 36 & 37 \\
\hline
\end{tabular}




\section{ORIENTAÇÕES TEÓRICO-METODOLÓGICAS DA COLETA DE DADOS}

Discutiremos nesta seção as orientações teórico-metodológicas que seguimos, bem como os procedimentos e recursos despendidos na pesquisa no intuito de minimizar os empecilhos e colaborar para o sucesso em pesquisas futuras.

As entrevistas que serão discutidas aqui foram obtidas através de gravações em vídeo com uma câmera Sony, modelo DCR-SR21. Em algumas oportunidades, recorremos a gravações de áudio feitas em minigravadores (Sony e Panasonic). Decidimos que o emprego de uma mesma marca de produtos colaboraria para a melhor qualidade de decodificação, reprodução e armazenamento de dados. Cuidado especial foi dirigido a pilhas e carregadores. A câmera fotográfica também foi um recurso bastante utilizado, por permitir registros contextuais importantes, que valorizam e ilustram o trabalho. No nosso caso, utilizou-se câmera Sony Cybershot DSC-W35.

Para a pesquisa de um Banco de Dados Lexical em uma comunidade com as características demonstradas anteriormente, em contexto de Educação do Campo, decidimos utilizar a concepção freireana (FREIRE, 1970, 1992) na abordagem de temas geradores, de onde se originaram os campos léxico-semânticos a serem estudados.

Desse modo, as unidades temáticas ficaram delimitadas por quatro eixos de interesse da comunidade:

a) história individual e coletiva;

b) fazer profissional;

c) relação sustentada com o meio ambiente e conscientização ambiental;

d) relações culturais (letras, arte, culinária e dança).

A melhor opção metodológica de trabalho com estas comunidades para fins de pesquisa de um Banco de Dados, para construção de dicionários baseados na oralidade, pareceu-nos serem os recursos da Variação e Mudança Linguística (WEINREICH, LABOV \& HERZOG, 1968; LABOV, 1972; SILVA-CORVALÁN, 1989; TARALLO, 1990) e, na sequência da pesquisa, da Dialetologia (KOCH, ALTENHOFEN \& KLASMANN-ALERS, 2011; AGUILERA-ALIB, 2001).

Em nosso caso, as entrevistas abrangeram conversações de caráter dirigido, semidirigido e livre. Por experiência própria, fomos levados a acreditar que as entrevistas de caráter espontâneo são as mais adequadas a uma pesquisa do tipo proposto aqui, em que o vernáculo flui naturalmente. Pudemos observar isso em uma gravação feita no trabalho comunitário, em que o gravador permaneceu ligado, sem que os informantes se dessem conta. No entanto, as situações de caráter espontâneo são difíceis de conseguir. Mesmo assim, seja nas gravações de conversação livre ou semidirigida, o assunto surgiu da necessidade de expressão própria do falante, a partir da instigação sociológica de temas peculiares à sua experiência de saber feito (FREIRE, 1970). Neste caso específico, os conteúdos das entrevistas giraram em torno da importância da reflexão sobre a identidade de sujeitos históricos com a profissão de pescadores artesanais; da importância da construção de uma câmara frigorífica ou de um tanque de criação de camarão ou de uma câmara defumadora; da importância da relação sustentada e preservação do ambiente em que vivem; de suas necessidades culturais. A conversação dirigida está direcionada para inquéritos na forma de questionário fonético-fonológico (QFF), questionário semântico-lexical (QSL), questionário morfossintático (QMS).

A constituição de um banco de dados com esta amplitude servirá de base lexicográfica para a construção de dicionário e, subsidiariamente, a estudos descritivos da língua portuguesa em uso 
no Brasil, em seus aspectos fonológicos, morfossintáticos e léxico-semânticos. Ao mesmo tempo em que serve para aprofundar os conhecimentos sobre a língua portuguesa em uso no Brasil, serve também para fazer a valoração da língua por meio das crenças e atitudes do falante em relação à sua variante linguística.

Isso posto, a constituição de um banco de dados com atenção especial ao aspecto lexical nos permitirá, consequentemente, propor a tipologia para um dicionário pedagógico (contrastivo monolíngue). Os inquéritos linguísticos ficaram constituídos da seguinte maneira:

a) Questionário fonético-fonológico (QFF);

b) Questionário morfossintático (QMS);

c) Questionário léxico-semântico;

d) Conversação livre (CL).

\section{CONCLUSÃO}

O trabalho de elaboração de dicionários não é tarefa fácil. As principais dificuldades para a construção de dicionários residem na sua delimitação, na sua arquitetura e na escolha da base lexical para seleção de verbetes. Este trabalho pretende ser uma contribuição para este último aspecto.

Neste trabalho, ficou ressaltado que a metodologia de coleta de dados dos campos da Variação e da Dialetologia serve a este papel. Há, porém, necessidade de muitos refinamentos.

Ainda ficam em aberto muitos pontos:

a) quanto à seleção lexical: os campos léxico-semânticos mais adequados, o tipo de entrevistas para coleta de dados, os recursos, as amostragens, etc;

b) quanto à arquitetura de dicionários: o tipo de dicionário e a forma de apresentação das unidades léxicas.

\section{REFERÊNCIAS}

ALERS. Atlas linguístico-etnográfico da região sul: cartas fonéticas e morfossintáticas. Organizadores: Walter Koch, Cleo Vilson Altenhofen e Mário Silfredo Klasmann. 2a . Ed. Porto Alegre: Editora da UFRG; Florianópolis: Ed. da UFSC, 2011.

ALERS. Atlas linguístico-etnográfico da região sul: cartas semântico-lexicais. Organizadores: Walter Koch, Cleo Vilson Altenhofen e Mário Silfredo Klasmann. 2a . Ed. Porto Alegre: Editora da UFRG; Florianópolis: Ed. da UFSC, 2011.

ALIB. Comitê Nacional do Projeto Alib (Brasil). Atlas Linguístico do Brasil. Londrina: Ed. UEL, 2001.

BÉJOINT, Henri. Modern lexicography: an introduction. Oxford: Oxford University Press, 2000.

BORBA, Francisco da Silva. Organização de dicionários: uma introdução à lexicografia. São Paulo: Editora UNESP, 2003. 
BORTONI-RICARDO, Stella Maris. Do campo para a cidade: estudo sociolinguístico de migração e redes sociais. São Paulo: Parábola Editorial, 2011.

DCE. Diretrizes Curriculares da Educação do Campo. Curitiba: SEED, 2006.

DURÃO, Adja Balbino de Amorim Barbieri. La interlengua. Madrid: arco Libros, 2007. (org.). Por uma lexicografia bilingue contrastiva. Londrina: UEL, 2009. (org.). Vendo o dicionário com outros olhos. Londrina: UEL, 2010.

FREIRE, Paulo. Pedagogia do Oprimido. 17ª . Ed. Rio de Janeiro: Paz e Terra, 1987 [1970]. . Pedagogia da Esperança: um encontro com a pedagogia do oprimido. Rio de Janeiro: Paz e Terra, 1992.

FREITAS, Waldomiro Ferreira de. História de Paranaguá: das origens à atualidade. Paranaguá: Instituto Histórico e Geográfico de Paranaguá (IHGP), 1999.

LABOV, William. Sociolinguistic Patterns. Oxford, GB: Basil Blackwell, 1972 [2008].

LADO, Robert. Introdução à linguistica aplicada. Tradução e notas: Vicente Pereira de Souza. Petrópolis/RJ: Vozes, 1971.

SANTOS, Antonio Vieira dos. Memória histórica chronológica, topographica e descriptiva da cidade de Paranaguá e do seu município. Curtyba: Tip. da "Livraria Mundial", 1922 [1850].

SELINKER, L. Rediscovering Interlanguage. London and New York: Longman, 1994.

SILVA-CORVALÁN, C. Sociolinguística: Teoría y análisis. Madrid: Editorial Alhambra, 1989.

TARALLO, Fernando. A pesquisa sociolinguística. São Paulo: Ática, 1990.

TOLEDO, Adilson do Rosário. Desenvolvimento de interlíngua na aquisição/aprendizagem da língua materna de crianças em fase inicial de escolarização. Tese (doutorado em Estudos da linguagem), UEL, 2011.

WEINREICH, Uriel; LABOV, William; HERZOG, Marvin. Fundamentos empíricos para uma teoria da mudança linguística. Tradução: Marcos Bagno. Revisão técnica: Carlos Alberto Faraco. São Paulo: Parábola Editorial, 2006 [1968].

WELKER, Herbert Andreas. Dicionários: Uma pequena introdução à lexicografia. $2^{\mathrm{a}}$. ed. revista e ampliada. Brasília: Thesaurus, 2004.

WERNER, R.; DURÃO, Adja B. de Amorim Barbieri; RUANO, Maria Angeles S. Equivalentes léxicos e informação semântica contrastiva no dicionário contrastivo português-espanhol. In: DURÃO, Adja Balbino de Amorim Barbieri (Org.). Por uma lexicografia bilíngue contrastiva. Londrina: UEL, 2009. 


\section{ANEXO 1 \\ PROJETO DE AMPARO AO PESCADOR - FICHA SOCIOINSTRUCIONAL}

1 Dados pessoais do informante

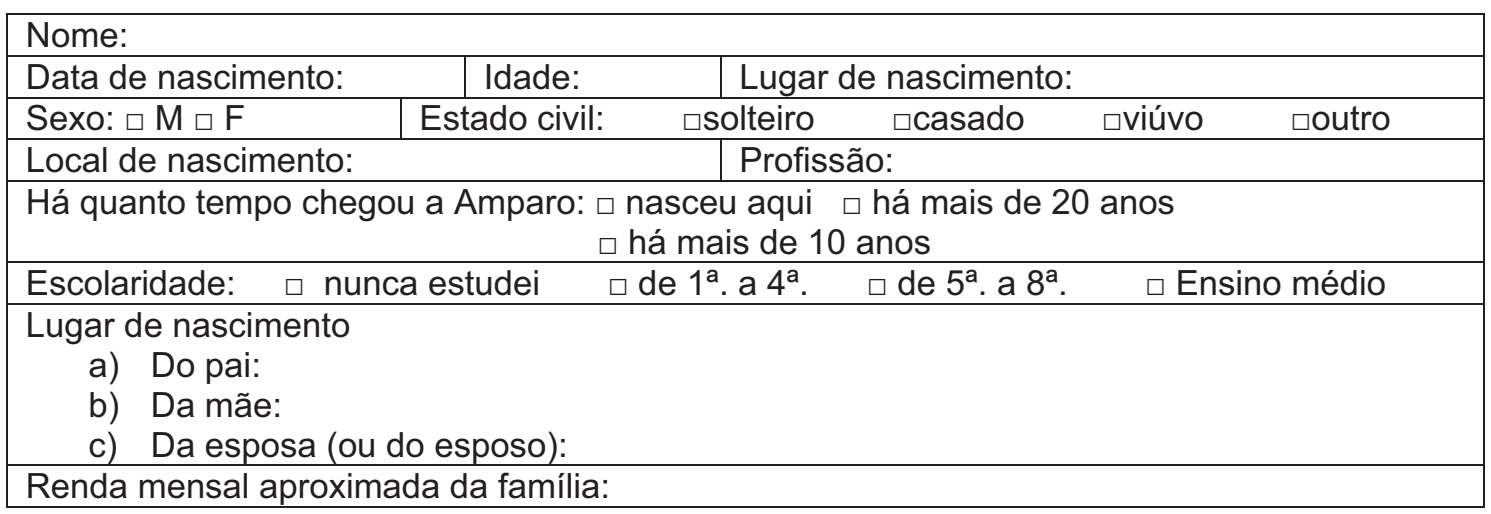

2 Dados gerais:

\begin{tabular}{|l|l|}
\hline Assiste TV: $\square$ todos os dias $\square$ às vezes $\square$ nunca \\
\hline Programas preferidos: $\square$ novela $\square$ esporte $\square$ noticiário $\square$ filme $\square$ religião \\
\hline Ouve rádio: $\square$ todos os dias $\square$ às vezes $\square$ nunca \\
\hline
\end{tabular}

3 Assinale de quais dessas atividades você gostaria de participar no Projeto da Petrobras: $\square$ culinária $\square$ artesanato $\square$ empreendedorismo $\square$ outra (citar qual)

4 Você já passou por alguma dificuldade no mar? Conte o que aconteceu:

5 Em poucas palavras, diga como você imagina o futuro de Amparo.

Concordo com os termos do Projeto de Amparo ao Pescador/Petrobras. 


\section{ANEXO 2}

\section{QUESTIONÁRIOS}

\section{QUESTIONÁRIO FONÉTICO-FONOLÓGICO}

a) Parte geral:

1. Que nome se dá a um lugar como esse, com águas por todos os lados?

2. Pai, mãe e filhos formam que grupo?

3. Crescendo, a menina vira mulher. E o menino?

4. O irmão de seu pai ou de sua mãe é o que do senhor?

5. O pai de sua mulher é seu sogro. E o senhor o que é dele?

6. Se a mulher é comadre, o homem é ...

7. Se numa casa todos saíram, quem ficou?

8. Que profissional contratamos para defender nossos interesses na justiça?

9. Que armas de fogo você conhece?

10. Se não quer ser incomodado, o senhor diz: me deixa em

11. Qual é o contrário de pouco?

12. Se alguma coisa não é verdade, ela é

13. O contrario de bom é

14. No inverno faz frio. No verão faz

15. Quando a água da chaleira esquenta e borbulha, dizemos que ela está

16. No ovo frito, há uma parte branca e outra amarela. Que nome elas têm?

17. A carne de porco não é magra porque tem .........

18. Como se chama aquele bichinho que se arrasta e solta uma gosma?

19. O contrário de noite é

20. Qual o nome do santo casamenteiro de 13 de junho?

21. Nas festas de igreja, qual o nome da caminhada que o povo faz atrás do andor?

22. Quando se vem de barco, qual o nome que se dá àquele lugar onde se desce e depois se anda pra chegar até aqui?

23. Como se chama aquele calendário que fica, geralmente, pendurado na parede?

b) Parte específica:

1. Qual o tipo de peixe mais comum que vocês pescam por aqui?

2. Onde, normalmente, vocês pescam por aqui?

3. Qual o nome que se dá àquele lugar lodoso e com vegetação característica, rico em crustáceos e outros animais, que fica na beirada da praia?

4. Qual o nome daquele crustáceo que vive entocado nesses lugares?

5. O que você usa pra pescar?

6. Qual o nome que se dá ao veículo de locomoção na água?

7. Qual o nome que se dá àquele pedaço de madeira usado pra impulsionar esse veículo? 
8. Qual o nome daquele crustáceo tortinho, como um anzol?

9. Onde se pesca esse tipo de pescado?

10. Como se pesca esse tipo de pescado?

11. Qual o nome que se dá àquele animal que vive na areia de baixio e se come cozido (lambe-lambe)?

12. Qual o nome daquele animal que se retira da pedra e se come cru ou cozido?

13. O frango, depois de grande, é chamado de

14. O ovo que fica muitos dias debaixo da galinha fica .......

15. Qual o nome que se dá àquela parte amarela que só a fêmea da tainha tem?

16. Que nome se dá àquela armadilha feita com varas do mangue pra pegar peixe?

17. Que nome se dá àquela armadilha pra pegar siri?

18. Que nome se dá àquela armadilha pra pegar passarinho?

19. Qual o nome do macaco que vive nessas matas?

20. Aquele animal que vive entocado no mato se chama

21. De manhã, se toma café com

22. Aquele fogão antigo, à lenha, chama-se

23. Qual o nome que se dá àquela época em que fica proibida a captura de peixe, camarão e caranguejo?

24. Qual o nome daquela coisa enroladinha que se põe na boca e faz fumaça?

25. Como se chama o tipo de dança mais comum por aqui?

26. Os fios do violão se chamam ......

27. Como se chama a parte da camisa que fica na ponta do braço?

28. Que nome se dá à maquina usada pra puxar a água do poço?

29. Como se chama a armadilha da aranha pra pegar insetos?

30. O que o sol faz com a roupa estendida no varal?

31. Como se chama aquela embarcação grande que fica atracada no porto?

32. Como se chama a parte de baixo do rosto? (mímica)

\section{QUESTIONÁRIO MORFOSSINTÁTICO}

I Sobre gênero:

1. O povo desse lugar diz meu barco, minha casa e não minha barco e meu casa. Como diria para as palavras seguintes:
Alface Alfinete
Cal Chaminé
Dó ( pena, pesar) Gilete

Sabonete Pá Saca-rolhas Fantasma Soja Tapa

2. O povo daqui diz um filho - uma filha; um menino uma menina. Como diria para:

a) Um alemão - uma .......

b) Um ladrão - uma .....

c) Um macho - uma ..... 
II Sobre número:

1. Quanto tempo é uma semana?

2. Quando escurece, o motorista tem que acender .....

3. Quanto tempo é um ano?

4. Complete: um lápis - muitos ...; um botão - muitos .....

5. Onde a abelha vai procurar mel?

6. Se quero que uma pessoa não veja, peço que ela feche ....

7. O que está preso no sabugo de milho?

III Sobre formas de tratamento:

a) Se você fosse pedir um favor à sua mãe ou a seu pai, como diria?

b) Imagine que você fosse convidar alguém pra almoçar em sua casa e você quisesse fazer um cozido de peixe. Explique como você faria o prato.

IV Sobre flexão verbal:

a) Presente: Faça a descrição de sua rotina diária (coisas que você sempre faz).

b) Passado: Você já passou por algum perigo de morte no mar.

c) Subjuntivo: você conhece alguma lenda do local.

V Discurso semidirigida

a) Se o senhor tivesse oportunidade de falar com alguma autoridade e fazer algum pedido, o que o senhor falaria?

b) O que o senhor espera do futuro?

\section{QUESTIONÁRIO LÉXICO-SEMÂNTICO}

a) Acidentes geográficos:

1. Como se chama uma elevação de terra bem alta?

2. O que entendem aqui por cerro?

3. O que entendem aqui por lomba?

4. O que entendem aqui por lombada?

5. O que entendem por coxilha?

6. O que entendem por perau?

7. Como se chama esse lado do morro?

8. Como se chama uma terra plana e baixa?

9. Como se chama a terra que permanece coberta de água cada vez que o rio sobe demais?

10. Como se chama um lugar que está ensopado de água e coberto de junco e outras plantas?

11. Como se chama uma grande quantidade de água em movimento? 
12. E uma quantidade menor?

13. E uma quantidade menor ainda?

14. O que você entende por sanga?

15. O que você entende por sangradouro?

16. O que você entende por vertedouro?

17. O que você entende por vertente?

18. O que você entende por restinga?

19. Como se chama a água parada depois de uma chuva?

20. Como se chama uma grande quantidade de água cercada de terra?

21. O que você entende por cacimba?

22. O que você entende por água salobra?

23. Como você chama a terra que fica de um lado e de outro do rio?

24. Como se chama o lugar onde a água sai da terra?

25. Quando as águas de um rio passam com muita força, diz-se que ele tem ...

26. O barco vai andando. De repente, toca no fundo. Que pode ter ali?

27. Como se chama o lugar onde se pode atravessar o rio a pé, a cavalo ou de carroça?

28. Como se chama a construção que serve para passar por cima de um rio?

29. E por cima de um arroio, às vezes com um tronco ou uma tábua?

30. Qual o nome que se dá quando, num rio, a água começa a girar, formando um buraco que puxa pra baixo?

31. Quando chove muito, o rio sobre muito e cobre uma grande extensão de terra. Que nome se dá a isso?

b) Fenômenos atmosféricos:

1. De que lado, normalmente, sopra o vento aqui? Como se chama esse vento?

2. Que outros tipos de ventos você conhece?

3. Fenômenos atmosféricos

4. Astros e tempo

5. Sistemas de pesos e medidas

6. Flora

7. Atividades agropastoris

8. Fauna

9. Corpo humano

10. Cultura e convívio

11. Ciclos da vida

12. Religião e crenças

13. Festas e divertimentos

14. Habitação

15. Alimentação e cozinha

16. Vestuário 


\section{CONVERSAÇÃO LIVRE}

a) O senhor já passou por alguma situação de perigo?

b) Se o senhor tivesse que fazer um pedido para benfeitoria neste lugar onde o senhor vive ao Prefeito ou ao Governador, por exemplo, o que pediria?

c) Como é a festa mais importante do lugar?

d) Quais as lendas do lugar?

e) O que o senhor acha do projeto da câmara frigorífica e da câmara de defumação?

f) O que o senhor espera para o futuro? 